\title{
Fertility Intentions and Awareness of Reproductive Aging among Final-Year Nigerian University Students
}

\author{
Olubukola Abimbola Oke \\ Department of Behavioural Studies, College of Management and Social Sciences, Redeemer's University, Ede, Nigeria \\ Email: okeo@run.edu.ng
}

How to cite this paper: Oke, O.A. (2019) Fertility Intentions and Awareness of Reproductive Aging among Final-Year Nigerian University Students. Open Journal of Social Sciences, 7, 37-52. https://doi.org/10.4236/jss.2019.75003

Received: March 25, 2019

Accepted: May 5, 2019

Published: May 8, 2019

Copyright $\odot 2019$ by author(s) and Scientific Research Publishing Inc. This work is licensed under the Creative Commons Attribution International License (CC BY 4.0).

http://creativecommons.org/licenses/by/4.0/

\section{c) (i) Open Access}

\begin{abstract}
The aim was to investigate university students' intentions and towards future parenthood and their awareness regarding reproductive aging by a cross sectional survey of 167 male (40.6\%) and 244 female (59.4\%) students across two university campuses in southwest Nigeria. Data was collected by a self-administered questionnaire and was analyzed using SPSS v.20. Analyses showed that female students were inclined to begin and end childbearing earlier than males $(\mathrm{p}=$ 0.000 ). Only $18.3 \%$ of male and $21.5 \%$ of female students correctly identified that female fertility markedly decreases by age 35 . Males were significantly more likely to overestimate female fecundity above age $35 ; \mathrm{p}=0.000$. Almost half of females (46.5\%) intended to have children after age 35 years but $42.9 \%$ overestimated the probability of conception above 35 years of age. Intention to continue childbearing into older ages based on incorrect perceptions of reproductive aging could lead to involuntary childlessness among a population that values childbearing. Appropriate education to improve fertility awareness and knowledge could help young adults properly plan and make informed reproductive decisions.
\end{abstract}

\section{Keywords}

University Students, Fertility Awareness, Reproductive Aging, Intentions, Nigeria

\section{Introduction}

There is a bias in the content of reproductive health information provided in formal and informal sex education for young people in the Nigerian society towards knowledge of the physiological anatomy, dangers of teenage pregnancy and prevention of sexually transmitted diseases [1]. There is inadequate aware- 
ness for young people about preconception health and future risks for primary or secondary infertility as a result of age-related fertility decline. This knowledge is particularly important because Sub-Saharan Africa, where Nigeria is situated, has one of the highest prevalence of infertility for less developed countries [2] [3]. Although there is paucity of national vital statistics, available reports suggest that the prevalence of infertility among married couples may be in the range of $20 \%-25 \%$ [4] [5] [6]. Considering the relative importance of children in Nigeria, couples who are considered childlessness are faced with a lot of social, emotional, psychological and financial trauma in the quest of having a child. Fertility decline due to reproductive aging begins in the mid-twenties for females, with a marked decrease in the mid-thirties, so it is imperative to address fertility awareness and intentions of university students who, due to their educational and career pursuits, are likely to postpone marriage and parenthood, and may be at risk for unintended infertility. Fertility awareness has been described as an individual's understanding of male and female reproductive anatomy and physiology as it relates to fertility [7]. This covers an understanding about their fertility potential at different stages of their lives and their ability to communicate about fertility issues together as a couple and with health professionals.

Human reproduction is profoundly influenced by age. Reference [8] explains that after menarche, the ability to reproduce increases with age to a plateau in the twenties, and then declines at an accelerating pace until menopause is reached. Though the level and shape of the schedules vary, these marked age variations in fertility are found in all populations, such that age is always taken into account for fertility analyses [9] [10]. While pregnancy can present health risks at any age, delaying the first pregnancy until a woman is at least 18 years old improves the chances that the mother and her baby will be healthy. It's also a biological fact that as women and men age, their potential to have children decreases, although the exact time when this starts to happen can vary among individuals [11]. This decrease is caused by low conception rate and increase in spontaneous abortion. Not all women of advanced reproductive age who wish to conceive experience infertility; good numbers of people have successfully had children in their late 30s or early 40s. However, across all populations' women younger than 35 and men younger than 45 have a better chance of having a child than people who are older [12]. This is true for spontaneous pregnancies and for pregnancies conceived through assisted reproductive treatments (ART) such as IVF (in-vitro fertilization).

Female fertility decline begins many years before the onset of menopause despite continued regular ovulation cycles, becoming pronounced after the age of 35 , and reaching almost nil by age 45 [13] [14] [15]. In addition, a woman who becomes pregnant at an advanced maternal age has greater risk of pregnancy complications like caesarean delivery, difficult labor, maternal and infant mortality or morbidity, and premature birth [16] [17]. In their review of studies on the effects of male age on semen quality and fertility [18] [19], concluded that although there is no absolute age at which men cannot father a child, increasing 
age is associated with a decline in semen volume, sperm motility, and sperm morphology, and sexual functioning, particularly over the age of 50 .

\section{Current Study}

The major objective of this study is to examine the fertility intentions of undergraduate Nigerian students in relation to their awareness of reproductive aging. In the literature there are many studies addressing multiple aspects of knowledge and beliefs about fertility throughout the life course, as well as some associated attitudes and behaviors. One particular population that has received considerable attention is university students, as they have just entered reproductive age and are facing competing interests, between their educational and career goals, marriage and childbearing [20] [21]. This interest arises because it has been noted empirically that women with higher education, particularly, tend to postpone marriage, and consequently, pregnancy [22].

In today's society, women's age at first birth continues to rise especially in more economically developed countries, with late pregnancies becoming rampant [23] [24]. When comparing Nigerian data with those of Western countries, the mean age of Nigerian first-time mothers is towards the lower end of the spectrum. The median age at first birth for women age 25 - 49 is 20.2 years [25]. Women with no education have their first birth four years earlier than women with secondary education (18.1 and 22.4 years, respectively). Expectedly, the median age for mothers with university education should be higher. Although there is no evidence for women postponing births until advanced maternal age in Nigeria, this study is imperative because, the number, of college educated women has increased over time which has considerable influence on age at first birth [26] [27].

Reports indicate that the percentage of females that completed tertiary education increased from 45.80 per cent in 2015 to 47.50 per cent in 2016 [28]. There are scant studies which have examined fertility awareness of men and women acquiring tertiary education-a group that is particularly at risk for delayed parenthood due to pursuit of educational and career activities. In addition, the study focus is on final year undergraduate students. A large proportion of this population are at the threshold of active reproductive behavior in terms of marriage and childbearing and, it would be particularly valuable to gain knowledge about their reproductive health awareness and fertility decision-making.

To date, the major university-based research has been conducted in Western countries [29] [30] [31] [32]. In Nigeria, fertility awareness of this peculiar population is considerably less documented. A search of literature brought up one Nigerian study [33], on awareness of female reproductive aging among medical and nonmedical students of Ahmadu Bello University, Zaria and Kaduna Polytechnic, Kaduna. Another study [34] was conducted on a non-university based sample. Studies have found remarkable gaps between the availability of medical information on fertility and reproductive behaviour and the actual awareness 
level of the general public. In two related studies, young university students in two Western countries were found to underestimate the age-related fertility decline. In a study of students in a Swedish university, [35] found that they planned to have their children at ages when female fertility has decreased. Similarly, [36] found that while there was a strong desire for future parenthood among American university students, they showed a lack of fertility awareness and overestimated both the likelihood of pregnancy after unprotected intercourse and the success rate of fertility treatment. Qualitative interviews of Canadian university students revealed similar findings [37].

The National Institute of Health [38], advocates that fertility awareness should be comprehensive of not only knowledge about a person's fertile time, it should include the ability to see and feel changes one's own body or circumstances that confirm and elucidate this knowledge, thereby linking knowledge to personal, observed experiences and consequently, meaningful/relevant action. In this vein, although delaying childbearing and marriage enables women to pursue their educational and career ambitions, advancing age reduces fecundity and could influence fertility intentions and behavior.

In Nigeria, a considerable proportion of young people are sexually active without the requisite information to safeguard and enhance their sexual and reproductive health [39] [40]. There are several sociocultural influences on attitudes towards sexuality and fertility in Nigeria, which inhibits the general level of knowledge and awareness. For example, open discussion of fertility issues is largely frowned upon, perceived stigma and embarrassment could lead to reluctance to discuss and address sexual health issues [41]. This restriction is more profound for those who do not conform to socially accepted standards of behaviour such as unmarried youths engaging in premarital sex. The negative attitude of parents and stakeholders, further exacerbated by religious conservatism, towards provision of sex education, as well as, sexual and reproductive health services in schools has further contributed to narrow sex education curriculum and programs for young people that do not take into account current realities of young girls [42] [43]. Lack of political will, reduced funding by government and relevant stakeholders, as well as ideological resistance are also contributing factors to the poor spread, access and use of sexual and reproductive health services by young people.

Thus, the specific objectives of this study is to 1) investigate students childbearing intentions; 2 ) assess awareness of students on age-related decline in men and women's fertility; and 3) compare intentions and awareness between male and female students.

\section{Methodology}

\subsection{Study Design}

The study used a cross-sectional design to examine awareness of issues related to reproductive aging and the childbearing intentions of university students. The 
study population consisted of a convenience sample of 500 hundred male and female students selected from the undergraduate student body of one private and one public university in South-West Nigeria. Data collection took place between March-April 2018. Inclusion criteria were being in the final academic year, and age between 18 and 29 years. Participants were recruited after formal classes with the help of course lecturers, when they were given brief information about the purpose of the study. It was emphasized that participation was voluntary and anonymous and, their willingness to complete the questionnaire was taken as informed consent. After informed consent, students were requested to individually fill out the questionnaire and hand it back. The final sample consisted of 411 students for a final response rate of $82.2 \%$. Excluded surveys included those with incomplete demographic data $(\mathrm{n}=17)$, and those with more than $20 \%$ of core questions left unanswered $(n=64)$. The sample consisted of $59.1 \%$ students in the management and social sciences (psychology, sociology, economics, accounting, finance and political science), $21.8 \%$ in arts and humanities (history and international studies, anthropology and theatre arts) and 19\% in the sciences (computer science, biochemistry, and microbiology).

\subsection{Instrument and Survey Questions}

The survey was based on a structured questionnaire with questions adopted from instruments developed by [35] and used in similar studies of university students [20] [30] [32] [36]. The questionnaire consisted of 23 into 3 domains: demographic and reproductive history (8 questions); future intentions for childbearing ( 7 questions), and knowledge of fertility issues which covered questions on male and female age-related fecundity and fertility (8 questions). Correct answers to the fertility awareness questions were determined based on published data in the studies cited above. The instrument was pre-tested on a small group of 20 students for clarity and wording, and there were no problems with comprehension.

\subsection{Data Analysis}

Descriptive statistics included frequencies and means with standard deviations (SD), with range (minimum - maximum). In order to compare the differences in answers between male and female students for continuous numerical data, independent $\mathrm{t}$-tests were used. Differences between genders in categorical variables (knowledge questions) were tested using cross tabulations and the Pearson's chi-squared test. Statistical significance was defined as $\mathrm{p}<0.05$. All statistical analysis was performed using SPSS 20.0 software (IBM).

\section{Results}

\subsection{Sample Characteristics}

The characteristics of the respondents can be found in Table 1 . The mean age was $23.3(\mathrm{SD}=2.4)$ years; $48.2 \%$ came from a family with $4-6$ children. Over 
Table 1. Demographic and reproductive characteristics of respondents.

\begin{tabular}{|c|c|c|c|}
\hline Characteristic & $\mathbf{n}$ & Mean (SD) & Range \\
\hline \multicolumn{4}{|l|}{ Age } \\
\hline Male & $167 / 411$ & $23.53(2.08)$ & \\
\hline Female & $244 / 411$ & $23.22(2.38)$ & \\
\hline \multicolumn{4}{|l|}{ Family Size } \\
\hline $1-3$ & $120 / 411$ & 29.2 & \\
\hline $4-6$ & $198 / 411$ & 48.2 & \\
\hline$\geq 7$ & $93 / 411$ & 22.6 & \\
\hline \multicolumn{4}{|l|}{ In a steady relationship } \\
\hline Yes & $186 / 411$ & 45.3 & \\
\hline No & $225 / 411$ & 54.7 & \\
\hline \multicolumn{4}{|l|}{ Ever been pregnant (self/partner) } \\
\hline Yes & $71 / 381$ & & \\
\hline No & $310 / 381$ & & \\
\hline \multicolumn{4}{|l|}{ Currently pregnant (self/partner) } \\
\hline Yes & $23 / 411$ & 5.6 & \\
\hline No & $388 / 411$ & 94.4 & \\
\hline \multicolumn{4}{|l|}{ No of children } \\
\hline 0 & $369 / 411$ & 89.8 & \\
\hline 1 & $33 / 411$ & 8.0 & \\
\hline 2 & $9 / 411$ & 2.2 & \\
\hline \multicolumn{4}{|c|}{ Source of reproductive health information } \\
\hline Internet & $199 / 411$ & 48.4 & \\
\hline Books & $60 / 411$ & 14.6 & \\
\hline Health care professional & $48 / 411$ & 11.7 & \\
\hline Friends & $40 / 411$ & 9.7 & \\
\hline Parents & $35 / 411$ & 8.5 & \\
\hline School & $29 / 411$ & 7.1 & \\
\hline
\end{tabular}

half of the students had a significant other $(42.1 \%$ in a relationship; $10.2 \%$ were engaged/married). The vast majority of participants (89.8\%) did not have children, $18.6 \%$ had had a previous pregnancy, and $5.8 \%$ were currently pregnant. When indicating where they received their reproductive health education, the most common method for seeking information was by using the Internet (48.4\%), followed by books (14.6\%), and through health care professionals $(11.7 \%)$.

\subsection{Intentions towards Childbearing}

Table 2 shows that the majority of respondents, who were not pregnant nor had children at the time of the study ( $\mathrm{n}=350)$, wished to become parents in the future (90.2\% among men and $97.4 \%$ among women). $48.3 \%$ of women were significantly more inclined to have a child within three years after graduation compared to $28.5 \%$ of men ( $\mathrm{p}=0.005)$. Majority of the respondents had no preference for the gender of their child (ren) (males $=81 / 147$ (55.1\%); females $=$ $101 / 196(53.7 \%)$ ), followed by $32.7 \%$ of males (48/154), and $20.7 \%$ of females (39/196) who showed a stronger preference for boys over girls. This constituted 
Table 2. Intentions towards child bearing ${ }^{\mathrm{a}}(\mathrm{n}=350)$.

\begin{tabular}{|c|c|c|c|}
\hline Questions & $\begin{array}{c}\text { Male }(\mathrm{n}=154) \\
\text { Mean }(\mathrm{SD}) \text { or N }(\%)\end{array}$ & $\begin{array}{l}\text { Female }(\mathrm{n}=196) \\
\text { Mean (SD) N (\%) }\end{array}$ & $\mathrm{p}$-value \\
\hline \multicolumn{4}{|l|}{ Want children } \\
\hline Yes & $138(90.2)$ & $191(97.4)$ & \\
\hline Uncertain & $15(9.8)$ & $5(2.6)$ & $0.005^{\mathrm{b}}$ \\
\hline Missing & 1 & 0 & \\
\hline \multicolumn{4}{|l|}{ Have a child within 3 years } \\
\hline Yes & $41(28.4)$ & $87(48.3)$ & \\
\hline No & $63(43.8)$ & $59(32.8)$ & \\
\hline Uncertain & $40(27.8)$ & $34(18.9)$ & $0.005^{\mathrm{b}}$ \\
\hline Missing & 10 & 16 & \\
\hline \multicolumn{4}{|l|}{ Preferred gender } \\
\hline More boys & $48(32.6)$ & $39(20.7)$ & \\
\hline More girls & $7(4.8)$ & $19(10.1)$ & \\
\hline Equal number & $11(7.5)$ & $29(15.4)$ & \\
\hline No preference & $81(55.1)$ & $101(53.7)$ & $0.000^{\mathrm{b}}$ \\
\hline Missing & 7 & 8 & \\
\hline Age at marriage & $28.7(1.38)$ & $26.2(1.25)$ & \\
\hline Range & $27-33$ & $24-28$ & $0.000^{c}$ \\
\hline Missing & 9 & 5 & \\
\hline Intended number of children & $3.2(0.77)$ & $3.1(0.70)$ & \\
\hline Range & $2-5$ & $1-4$ & $0.115^{\mathrm{c}}$ \\
\hline Missing & 11 & 5 & \\
\hline Age at first child & $29.5(1.31)$ & $26.8(1.51)$ & \\
\hline Range & $27-35$ & $24-30$ & $0.000^{c}$ \\
\hline$\%$ want child at $\geq 30$ & $96(67.1)$ & $19(9.9)$ & \\
\hline Missing & 11 & 5 & \\
\hline Age at last child & $37.3(1.97)$ & $33.5(2.1)$ & \\
\hline Range & $32-40$ & $30-38$ & $0.000^{c}$ \\
\hline$\%$ want child at ages $\geq 35$ & $132(92.3)$ & $82(42.9)$ & \\
\hline Missing & 11 & 5 & \\
\hline
\end{tabular}

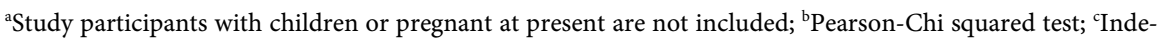
pendent t-test.

a statistically significant difference between the genders $(p=0.000)$. The mean desired age at marriage was significantly higher for males at $28.7 \pm 1.38$ than for females at $26.2 \pm 1.24(\mathrm{t}(334)=12.94, \mathrm{p}=0.000)$. The majority wanted to have about three children (male $=3.2 \pm 0.77$; female $=3.1 \pm 0.70$ ). Females were significantly more inclined to begin and end childbearing at younger ages than males. The mean desired age at which participants desired to have their first child was $29.5 \pm 1.32$ for males and $26.8 \pm 1.51$ for females $(\mathrm{t}(332)=11.19, \mathrm{p}=$ 0.000 ). While no male wished to have children before age 27 , females wanted to start at age 24. The mean desired age to have their last child was at $37.4 \pm 1.97$ years for males and $33.5 \pm 2.07$ for females $(\mathrm{t}(332)=11.76, \mathrm{p}=0.000)$.

\subsection{Knowledge of Reproductive Aging}

In a series of questions, participants stated their understanding regarding fertili- 
ty-related issues (Table 3). Most respondents answered correctly that fertility reduces as one ages $(74.3 \%, 85.2 \%$ females). More than fifty percent of males significantly overestimated the age of optimal female fertility compared to $48.8 \%$ of females $(\mathrm{p}=0.001)$. Although a greater proportion of respondents correctly identified the ages at which female fertility markedly declines, $56.2 \%$ of males overestimated it to 45 - 49 years and $42.5 \%$ of females overestimated to $40-44$ years; with men estimating the age to be significantly higher than women ( $\mathrm{p}=$

Table 3. Questions and answers regarding reproductive aging and fertility.

\begin{tabular}{|c|c|c|c|c|}
\hline Questions & Categories & $\begin{array}{c}\text { Male } \mathrm{n} \\
(\%)\end{array}$ & $\begin{array}{l}\text { Female } \mathrm{n} \\
(\%)\end{array}$ & $\mathrm{p}$-value \\
\hline \multirow{2}{*}{$\begin{array}{l}\text { 1) Do you believe that your } \\
\text { reproductive capability decreases } \\
\text { as you get older? }\end{array}$} & Yes $^{\mathrm{a}}$ & $124(74.3)$ & $208(85.2)$ & \multirow[b]{2}{*}{0.007} \\
\hline & No & $43(25.7)$ & $36(14.8)$ & \\
\hline \multirow{4}{*}{$\begin{array}{l}\text { 2) At what age is a woman } \\
\text { most fertile? }\end{array}$} & $15-19$ & $15(9.0)$ & $30(12.3)$ & \multirow{4}{*}{0.001} \\
\hline & $20-24^{\mathrm{a}}$ & $58(34.7)$ & $95(38.9)$ & \\
\hline & $25-29$ & $83(49.7)$ & $119(48.8)$ & \\
\hline & $30-34$ & $11(6.6)$ & $0(0.0)$ & \\
\hline \multirow{5}{*}{$\begin{array}{l}\text { 3) At what age does a woman's } \\
\text { fertility begin to decline? }\end{array}$} & $30-34$ & $9(5.9)$ & $0(0.0)$ & \multirow{5}{*}{0.000} \\
\hline & $35-39^{a}$ & $19(12.4)$ & $49(21.5)$ & \\
\hline & $40-44$ & $39(25.5)$ & $97(42.5)$ & \\
\hline & $45-49$ & $86(56.2)$ & $82(36.0)$ & \\
\hline & Missing & 14 & 16 & \\
\hline \multirow{6}{*}{$\begin{array}{l}\text { 4) What age does male fertility } \\
\text { starts to decline? }\end{array}$} & $40-44^{\mathrm{a}}$ & $10(6.4)$ & $6(2.6)$ & \multirow{6}{*}{0.033} \\
\hline & $45-49$ & $13(8.3)$ & $15(6.5)$ & \\
\hline & $50-54$ & $30(19.1)$ & $30(13.0)$ & \\
\hline & $55-59$ & $41(26.1)$ & $53(22.9)$ & \\
\hline & $\geq 60$ & $63(40.1)$ & $127(55.0)$ & \\
\hline & Missing & 10 & 13 & \\
\hline \multirow{5}{*}{$\begin{array}{l}\text { 5) If a woman and a man have } \\
\text { regular unprotected intercourse } \\
\text { during a period of } 1 \text { year: How large } \\
\text { is the chance she will become } \\
\text { pregnant if she is } 25 \text { - } 30 \text { years? }\end{array}$} & $0 \%-69 \%$ & $9(5.8)$ & & \multirow{5}{*}{0.001} \\
\hline & $70 \%-79 \%^{a}$ & $25(16.1)$ & $\begin{array}{l}10(0.9) \\
21(91)\end{array}$ & \\
\hline & $80 \%-89 \%$ & $40(25.8)$ & $105(455)$ & \\
\hline & $90 \%-100 \%$ & $81(52.3)$ & & \\
\hline & Missing & 12 & $89(38.5)$ & \\
\hline \multirow{5}{*}{$\begin{array}{l}\text { 6) If a woman and a man have } \\
\text { regular unprotected intercourse } \\
\text { during a period of } 1 \text { year: How large } \\
\text { is the chance she will become } \\
\text { pregnant if she is } 35 \text { - } 40 \text { years? }\end{array}$} & $0 \%-49 \%$ & $6(3.8)$ & $53(23.2)$ & \multirow{5}{*}{0.000} \\
\hline & $50 \%-59 \%^{\mathrm{a}}$ & $30(19.2)$ & $69(30.3)$ & \\
\hline & $60 \%-69 \%$ & $93(59.6)$ & $62(27.2)$ & \\
\hline & $70 \%-100 \%$ & $27(17.3)$ & $44(19.3)$ & \\
\hline & Missing & 11 & 16 & \\
\hline \multirow{4}{*}{$\begin{array}{l}\text { 7) A } 40 \text {-year-old woman undergoing } \\
\text { in-vitro fertilization (IVF) has the } \\
\text { best chance of becoming pregnant } \\
\text { when using eggs donated by a } \\
\text { younger woman }\end{array}$} & True $^{a}$ & $49(31.4)$ & $65(27.9)$ & \multirow{4}{*}{0.689} \\
\hline & False & $81(51.9)$ & $131(56.2)$ & \\
\hline & Don't know & $26(16.7)$ & 37 (15.9) & \\
\hline & Missing & 11 & 11 & \\
\hline \multirow{5}{*}{$\begin{array}{l}\text { 8) when is a woman fertile within a } \\
\text { menstrual cycle }\end{array}$} & Ovulation day & $63(41.2)$ & $74(31.9)$ & \multirow[t]{5}{*}{0.073} \\
\hline & 4 days before & $31(20.3)$ & $69(29.7)$ & \\
\hline & 3 days after & $25(16.3)$ & $47(20.3)$ & \\
\hline & One week after & $34(12.2)$ & $42(18.1)$ & \\
\hline & Missing & 14 & 12 & \\
\hline
\end{tabular}

${ }^{\mathrm{a}}$ Correct response according to published literature. 
0.000). With regard to the onset of male fertility decline, females were significantly more likely to overestimate the onset of male fertility decline to 60 years and above $(40.1 \%$ males, $55.0 \%$ females; $\mathrm{p}=0.033)$. Both genders overestimated a couple's ability to conceive if having unprotected sex for a period of one year, for a woman aged $25-30$, with $52.3 \%$ of male estimating it at $90 \%-100 \%$ ( $\mathrm{p}=$ 0.001 ). However, in comparison with males, the females were significantly more likely to underestimate fecundity at when the woman was aged $35-40$ years ( $\mathrm{p}=$ 0.020). Surprisingly, more males $(31.4 \%)$ than females $(27.9 \%)$ correctly assumed that the success of an IVF procedure would be greater for a woman aged 40 years of age if she used eggs donated by a younger woman. Finally, when asked when in the menstrual cycle a woman is fertile, only $26 \%$ of both genders correctly identified a woman's fertile period in a menstrual cycle.

\section{Discussion and Theoretical Implications of Study Findings}

This study assessed differences in knowledge and perceptions of reproductive aging among final year university students. Respondents highly valued parenthood and $94.3 \%$ had intentions to marry and become parents, with females expressing their intention to begin childbearing earlier than the males. The mean desired number of children for respondents who were not yet parents was $3.2 \pm$ 0.7, which is comparable to results from the 2013 Nigerian Demographic Health survey [25]. Women who have more than secondary education have an average of 3.1 children, while women with no education have 6.9 children. The result is supported by empirical evidence to the effect that education, especially of women has an inverse relationship with their fertility rate [44] [45] [46]. All these studies prove that fertility intentions are an important channel through which education affects reproductive behavior. Reference [47] has stated the mechanisms through which this works: 1) declining fecundity with age, which may result in involuntary childlessness; 2) repeated postponements in marriage or childbearing, because of competing activities; 3) lack of a partner, or partnership instability.

Results from questions on fertility knowledge shows that the students overestimated the age of optimal fertility in females and demonstrated a significant lack of awareness concerning the natural, age-related decline in male and female fertility-this finding is consistent with studies conducted with university students in America, Denmark, Sweden, Finland, Canada, Italy and Israel [20] [21] [36] [48] [49]. Respondents thought that decrease in fertility occurs later than it really does. This result is noteworthy because even if only $9.9 \%$ of female respondents desired to have their first child before the age of 30 years, $42.9 \%$ indicated to continue childbearing until ages when female fertility is markedly decreased (35 - 38). It is also important to note because Fecundity was overestimated by $81.4 \%$ and $62.7 \%$ of both genders for women aged $25-30$ and $35-40$ years respectively. The age at which there is a slight decrease in female fertility is 25 - 29 years, as published in literature. Continued childbearing into older ages 
may have implications for desired and actual completed fertility of individual women, due to possible cases of secondary infertility which may delay conception.

The results of this present study further shows that one-fourth of males and $42.5 \%$ of females inaccurately believed that female fertility markedly declines only after the age of 40 , with over half of males and $36 \%$ of females overestimating that the decline takes place after the age of 44 . Ninety two percent of both genders also significantly overestimated the onset of decline in male fertility, with most setting it at 60 years and above. This is understandable, because in most African societies, cultural and religious orientation towards infertility is usually attributed to the female gender. Looking at the news and happenings in the society, much older men had married and had children successfully despite their advanced age. It should be emphasized, however, that most of these men marry much younger women, which could be a boost for their fertility.

With regard to spontaneous pregnancy, women's chances of conception were overestimated for both age groups. The highest overestimation concerned the likelihood of 35- to 40-year-old women conceiving spontaneously. Male respondents provided responses that significantly overestimated female fecundity especially at advanced ages, compared to the female respondents. This agrees with results of other studies which showed that males had lower fertility knowledge compared to females [35] [48]. A large proportion of both genders didn't know the accurate female fertile period within a menstrual cycle. Possible implications of such accumulation of poor knowledge according to [34], is portrayed in how couples use this knowledge to try to conceive, which may translate to late presentation for health care when conception delays. Infertility usually is diagnosed in a woman aged less than 30 years if she has not become pregnant after 1 year of unprotected intercourse. However, if she is 35 or older, the evaluation should begin after 6 months of trying unsuccessfully to conceive. An important point to consider as probable cause of this trend of overestimation is the media portrayal of successes of women who have children at older ages. But as noted by [21], the means necessary to achieve such pregnancies may have been overlooked by the media and the respondents, leading to ignorance and over-optimism of female fecundity at advanced ages.

Increasingly, the internet has become a veritable source of information for a lot of people, as indicated in other studies [50] [51]. This was confirmed in this study where the majority (48.4\%) stated that their preferred source of reproductive health information is the Internet. only $11.7 \% \%$ of respondents reported seeking information from a health care professional which may likely be because majority had not begun childbearing. Schools were the least likely source of information (7.1\%) which reflects the lack of emphasis on sex education in the Nigerian society. Where formal education is provided, it is heavily biased towards knowledge of sexual anatomy and promoting abstinence, with little or no information being provided on fertility issues. 
At present, given the limited content of sexual and reproductive health education available to young adults in the society, there is an urgent need for increasing public awareness about the impact of ageing on reproductive outcomes. The findings from this current study support this call, as there is an indication that there is poor awareness of age-related fertility decline. In an emerging economy like Nigeria, high cost of living and need for economic security causes delay in family formation for this group of educated people. Final year university students who are on the verge of going out into the larger society to further their educational or career plans need this knowledge to properly plan for parenthood, in order to avoid the pitfalls of involuntary infertility Prevailing social norms on childbearing places huge socioeconomic, psychological and financial burden on couples who have to deal with delays in childbearing in situations where it could have prevented, given the right information. Although, assisted reproductive technologies are now available for affected couples, but the cultural and economic costs associated with assessing these technologies is too high a cost to bear for a vast majority especially in an emerging economy like Nigeria. Religious and cultural norms prevent some individuals from accepting the use of reproductive technologies like the IVF or surrogacy because of issues related to use of donor eggs or sperms, non-coital reproduction, and every woman wanting to "carry her own child" [52] [53] [54] [55]. Early and adequate awareness still remains the best key for involuntary infertility prevention.

\section{Limitations of the Study and Directions for Future Research}

Findings from this study should be interpreted in the context of its limitations. A major limitation of this study is the potential of bias inherent in using the convenient sampling method. This present study sample may therefore not be fully representative of the university population as a whole. Although the magnitude of this bias cannot be assessed, it may have had a minimal impact as respondents were recruited across different campus locations and various fields of study. Responses to the fertility knowledge questions could have been left open-ended, to allow students give actual figures, in order to reduce overestimation of proportions by respondents. Nevertheless, since the close-ended questions, were adopted from previously established and well acclaimed studies, this should be at a minimum. In addition, because this was a university-based study, it may not necessarily reflect the prevalence of awareness and intentions of similarly aged non-university population.

Despite these limitations, the results of this study add to the literature assessing fertility awareness among young people in Nigeria, where there is paucity of research on the interaction between knowledge about reproductive aging and family intentions. Another strength of this study is the inclusion a question on male fertility decline. An earlier university-based Nigerian study by [33] did not include any question on male fertility. Studying student's knowledge on male age-related fertility is also important because they desire parenthood as much as women and although male age is less significant in determining couple fertility, 
it contributes to the possibility of conceiving. To optimize their chance of becoming fathers, men need to be aware of the factors that influence their own and their partner's fertility.

Similar cross-sectional studies are also suggested across the Nigerian society, among different categories of population, especially non-university and older reproductive aged couples. Future university-based studies should include a study of postgraduate students, as they are at greater risk of involuntary infertility, due to their advanced age and career aspirations. An examination of lifestyle factors which interact with age to affect fertility should also be considered.

\section{Conclusion}

This present study has contributed to the literature on contemporary attitudes towards parenthood among university students and also has identified significant important gaps in male and female awareness on fertility along the reproductive lifespan. These include general poor knowledge of limits of male and female reproductive life, fertile period in the menstrual cycle, and mechanism of IVF success for older women. Most importantly, the results indicate a strong association between gender and fertility knowledge. Male respondents were more likely to overestimate female fecundity especially at older ages, which suggests that they should be targeted in education and information campaigns. There should be concerted efforts by relevant stakeholders to increase fertility knowledge among university students in general.

\section{Conflicts of Interest}

The author declares no conflicts of interest regarding the publication of this paper.

\section{References}

[1] Kunnuji, M. (2012) Atypical Adolescent Sexual Behaviour: A Study of Involvement in Triolism and Same Gender Sex in Lagos, Nigeria. International Journal of Sociology and Anthropology, 4, 8-12. https://doi.org/10.5897/ijsa11.112

[2] Etuk, S.J. (2009) Reproductive Health: Global Infertility Trend. Nigerian Journal of Physiological Sciences, 24, 85-90. https://doi.org/10.4314/njps.v24i2.52920

[3] Mascarenhas, M.N., Flaxman, S.R., Boerma, T., Vanderpoel, S. and Stevens, G.A. (2012) National, Regional, and Global trends in Infertility Prevalence Since 1990: A Systematic Analysis of 277 Health Surveys. PLoS Medicine, 9, 1-12. https://doi.org/10.1371/journal.pmed.1001356

[4] Odusoga, O., Oloyede, O., Adewunmi A.A. and Fakoya, T. (2002) Experience with the Laparascopy in the Evaluation of Infertile Women in Sagamu. Nigerian Journal of Clinical Practice, 5, 127-129.

[5] Olatunji, A.O. and Sule-Odu, A.O. (2003) The Pattern of Infertility Cases at a University Hospital. West African Journal of Medicine, 22, 205-207. https://doi.org/10.4314/wajm.v22i3.27950

[6] Ukpong, D.I. and Orji, E.O. (2006) Mental Health of Infertile Women in Nigeria. Turkish Journal of Psychiatry, 17, 259-265. 
[7] Pyper, C.M.M (1997) Fertility Awareness and Natural Family Planning. European Journal of Contraception and Reproductive Health Care, 2, 131-146. https://doi.org/10.3109/13625189709167468

[8] Steinberg, L. (2014) Age of Opportunity: Lessons from the New Science of Adolescence. Houghton Mifflin Harcourt, Boston, MA.

[9] Bopp, B. and Seifer, D. (2008) Age and Reproduction. Global Library of Women's Medicine.

[10] Clark, S.J., Eaton, J.W., Elmquist, M.M., Otten-weiller, N.R. and Snavely, J.K. (2008). Demographic Consequences of HIV Epidemics and Effects of Different Male Circumcision Intervention Designs: Suggestive Findings from Microsimulation. Center for Statistics and the Social Sciences, Seattle.

[11] Alviggi, C., Humaidan, P., Howles, C., Tredway, D. and Hillier, S. (2009) Biological versus Chronological Ovarian Age: Implications for Assisted Reproductive Technology. Reproductive Biology and Endocrinology, 7, 101. https://doi.org/10.1186/1477-7827-7-101

[12] Salihu, H.M., Wilson, R.E., Alio, A.P. and Kirby, R.S. (2008) Advanced Maternal Age and Risk of Antepartum and Intrapartum Stillbirth. Journal of Obstetrics and Gynaecology Research, 34, 843-850. https://doi.org/10.1111/j.1447-0756.2008.00855.x

[13] Nikolaou, D. and Templeton, A. (2004) Early Ovarian Ageing. European Journal of Obstetrics, Gynecology and Reproductive Biology, 113, 126-133. https://doi.org/10.1016/j.ejogrb.2003.09.024

[14] Djahanbakhch, O., Ezzati, M. and Zosmer, A. (2007) Reproductive Ageing in Women. Journal of Pathology, 211, 219-231. https://doi.org/10.1002/path.2108

[15] te Velde, E.R. and Pearson, P.L. (2002) The Variability of Female Reproductive Ageing. Human Reproduction Update, 8, 141-154.

https://doi.org/10.1093/humupd/8.2.141

[16] Luke, B. and Brown, M.B. (2007) Maternal Risk Factors For Potential Maltreatment Deaths among Healthy Singleton and Twin Infants. Twin Research and Human Genetics, 10, 778-785. https://doi.org/10.1375/twin.10.5.778

[17] Usta, I.M. and Nassar, A.H. (2008) Advanced Maternal Age. Part I: Obstetric Complications. American Journal of Perinatology, 25, 521-534. https://doi.org/10.1055/s-0028-1085620

[18] Sartorius, G.A. and Nieschlag, E. (2010) Paternal Age and Reproduction. Human Reproduction Update, 16, 65-79. https://doi.org/10.1093/humupd/dmp027

[19] Kidd, S.A., Eskenazi, B. and Wyrobek, A.J. (2001) Effects of Male Age on Semen Quality and Fertility: A Review of the Literature. Fertility and Sterility, 75, 237-248. https://doi.org/10.1016/s0015-0282(00)01679-4

[20] Bretherick, K.L., Fairbrother, N., Avila, L., Harbord, S.H. and Robinson, W.P. (2010) Fertility and Aging: Do Reproductive-Aged Canadian Women Know What They Need to Know? Fertility and Sterility, 93, 2162-2168. https://doi.org/10.1016/j.fertnstert.2009.01.064

[21] Hashiloni-Dolev, Y., Kaplan, A. and Shkedi-Rafid, S. (2011) The Fertility Myth: Israeli Students' Knowledge Regarding Age-Related Fertility Decline and Late Pregnancies in an Era of Assisted Reproduction Technology. Human Reproduction, 26, 3045-3053. https://doi.org/10.1093/humrep/der304

[22] United Nations Population Division (2012) World Population Prospects: The 2012 Revision. http://esa.un.org/unpd/wpp/unpp/panel_indicators.htm 
[23] Zeman, K., Beaujouan, E., Brzozowska, Z. and Sobotka, T. (2018) Cohort Fertility Decline in Low Fertility Countries: Decomposition Using Parity Progression Ratios. Demographic Research, 38, 651-690. https://doi.org/10.4054/demres.2018.38.25

[24] Sobotka, T. and Beaujouan, E. (2018) Late Motherhood in Low-Fertility Countries: Reproductive Intentions, Trends and Consequences. In: Stoop, D., Ed., Preventing Age Related Fertility Loss, Springer, Cham, 11-29. https://doi.org/10.1007/978-3-319-14857-1_2

[25] National Population Commission (NPC) (2014) Nigeria Demographic and Health Survey 2013. Abuja, Nigeria: National Population Commission and ICF Macro.

[26] Akpa, O. and Ikpotokin, O. (2012) Modeling the Determinants of Fertility among Women of Child-Bearing Age in Nigeria: Analysis Using Generalized Linear Modeling Approach. International Journal of Humanities and Social Science, 2, 167-176.

[27] Gayawan, E. and Adebayo, S. (2013) A Bayesian Semiparametric Multilevel Survival Modelling of Age at First Birth in Nigeria. Demographic Research, 28, 1339-1372. https://doi.org/10.4054/demres.2013.28.45

[28] National Bureau of Statistics (NBS) and United Nations Children's Fund (UNICEF) (2018) Nigeria-Multiple Indicator Cluster Survey (MICS5) 2016, Fifth Round. Federal Government of Nigeria (FGN), February 2018.

[29] Brennan D.P., Pirritano, M., Tucker, L. and Lampic, C. (2012) Fertility Awareness and Parenting Attitudes among American Male and Female Undergraduate University Students. Human Reproduction, 27, 1375-1382,

https://doi.org/10.1093/humrep/des011

[30] Chan, C.H., Chan, T.H., Peterson, B.D., Lampic, C. and Tam, M.Y. (2015) Intentions and Attitudes towards Parenthood and Fertility Awareness among Chinese University Students in Hong Kong: A Comparison with Western Samples. Human Reproduction, 30, 364-372. https://doi.org/10.1093/humrep/deu324

[31] Bunting, L., Tsibulsky, I. and Boivin, J. (2013) Fertility Knowledge and Beliefs about Fertility Treatment: Findings from the International Fertility Decision-Making Study. Human Reproduction, 28, 385-397. https://doi.org/10.1093/humrep/des402

[32] Sørensen, N.O., Marcussen, S., Backhausen, M.G., Juhl, M., Schmidt, L., Tydén, T. and Hegaard, H.K. (2016) Fertility Awareness and Attitudes towards Parenthood among Danish University College Students. Reproductive Health, 13, 146. https://doi.org/10.1186/s12978-016-0258-1

[33] Adesiyun, A. Ameh, N., Zayyan, M., Umar-Sullayman, H., Avidime, S., Koledade, K. and Bakare, F. (2014) Awareness of Female Reproductive Aging among Undergraduate Students and Attitudes toward Parenthood. Journal of Gynecology and Obstetrics, 2, 123-126.

[34] Ajayi, A.B., Ajayi, V.D., Oyetunji, I. Biobaku, O., Odiete, E. and Afolabi, B. (2016) Online Fertility Survey. Medical and Clinical Review, 2, 33.

https://doi.org/10.21767/2471-299X.1000042

[35] Lampic, C., Svanberg, A.S., Karlstrom, P. and Tyden, T. (2006) Fertility Awareness, Intentions Concerning Childbearing, and Attitudes towards Parenthood among Female and Male Academics. Human Reproduction, 21, 558-564. https://doi.org/10.1093/humrep/dei367

[36] Peterson, B.D., Pirritano, M., Tucker, L. and Lampic, C. (2012) Fertility Awareness and Parenting Attitudes among American Male and Female Undergraduate University Students. Human Reproduction, 27, 1375-1382.

https://doi.org/10.1093/humrep/des011

[37] Sabarre, K.A., Khan, Z., Whitten, A.N., Remes, O. and Phillips, K.P. (2013) A Qua- 
litative Study of Ottawa University Students' Awareness, Knowledge and Perceptions of Infertility, Infertility Risk Factors and Assisted Reproductive Technologies (ART). Reproductive Health, 10, 41. https://doi.org/10.1186/1742-4755-10-41

[38] National Institute for Health (NIH) (2009) NIH Science of Behavior Change Meeting Summary. 15-16 June 2009.

[39] Bankole, A., Sedgh, G., Okonofua, F., Imarhiagbe, C., Hussain, R. and Wulf, D. (2009) Barriers to Safe Motherhood in Nigeria. Guttmacher Institute, New York, March 2009.

[40] Okereke, C.I. (2010) Unmet Reproductive Health Needs and Health-Seeking Behaviour of Adolescents in Owerri, Nigeria. African Journal of Reproductive Health, 14, 43-54.

[41] Ogundipe, S.O. and Ojo, F.Y. (2015). Adolescent Sexuality Education in Contemporary Nigeria and Its Implication for Pastoral Counselling. International Journal of Scientific and Research Publications, 5, 1-8.

[42] Oshi, D.C., Nakalema, S. and Oshi, L.L. (2005) Cultural and Social Aspects of HIV/AIDS Sex Education in Secondary Schools in Nigeria. Journal of Biosocial Science, 37, 175-183. https://doi.org/10.1017/s0021932004006820

[43] Allen, K.R. and Brooks, J.E. (2012) At the Intersection of Sexuality, Spirituality, and Gender: Young Adults' Perceptions of Religious Beliefs in the Context of Sexuality Education. American Journal of Sexuality Education, 7, 285-308. https://doi.org/10.1080/15546128.2012.740859

[44] Liefbroer, A.C. (2009) Changes in Family Size Intentions across Young Adulthood: A Life-Course Perspective. European Journal of Population, 25, 363-386. https://doi.org/10.1007/s10680-008-9173-7

[45] Testa, M.R. (2012) Childbearing Preferences and Family Size in Europe: Evidence from the 2011 Eurobarometer Survey. European Demographic Research Paper 1. Vienna Institute of Demography of the Austrian Academy of Sciences.

[46] Iacovou, M. and Tavares, L. (2011) Yearning, Learning, and Conceding: Reasons Men and Women Change Their Childbearing Intentions. Population and Development Review, 37, 89-123. https://doi.org/10.1111/j.1728-4457.2011.00391.x

[47] Morgan, S.P. and Rackin, H. (2010) The Correspondence Between Fertility Intentions and Behavior in the United States. Population Development Review, 36, 91-118. https://doi.org/10.1111/j.1728-4457.2010.00319.x

[48] Vassard, D., Lallemant, C., Nyboe, A., Macklon, N. and Schmidt, L. (2016) A Population-Based Survey on Family Intentions and Fertility Awareness in Women and Men in the United Kingdom and Denmark. Upsala Journal of Medical Sciences, 121, 244-251. https://doi.org/10.1080/03009734.2016.1194503

[49] Rovei, V., Gennarelli, G., Lantieri, T., Casano, S., Revelli, A. and Massobrio, M. (2010) Family Planning, Fertility Awareness and Knowledge about Italian Legislation on Assisted Reproduction among Italian Academic Students. Reproductive Biomedicine Online, 20, 873-879. https://doi.org/10.1016/j.rbmo.2010.03.024

[50] Baurele, B.S. (2003) How Will Internet Use Affect the Patient? A Review of Computer Network and Closed Internet-Based System Studies and The Implications in Understanding How the Use Of the Internet Affects Patient Populations. Journal of Health Psychology, 8, 25-38. https://doi.org/10.1177/1359105303008001427

[51] Hammarberg, K., Setter, T., Norman, R.J., Holden, C.A., Michelmore, J. and Johnson, L. (2013) Knowledge about Factors that Influence Fertility among Australians of Reproductive Age: A Population-Based Survey. Fertility and Sterility, 99, 502-507. https://doi.org/10.1016/j.fertnstert.2012.10.031 
[52] Birkhäuser, M. (2013) Ethical Issues in Human Reproduction: Protestant Perspectives in the Light of European Protestant and Reformed Churches. Gynecology and Endocrinology, 29, 955-959. https://doi.org/10.3109/09513590.2013.825716

[53] Lanzone, A. (2013) Ethical Issues in Human Reproduction: Catholic Perspectives. Gynecology and Endocrinology, 29, 953-954.

https://doi.org/10.3109/09513590.2013.825717

[54] Bello, F.A., Akinajo, O.R. and Olayemi, O. (2014) In-Vitro Fertilization, Gamete Donation and Surrogacy: Perceptions of Women Attending an Infertility Clinic in Ibadan, Nigeria. African Journal of Reproductive Health, 18,127-133.

[55] Fadare, J.O. and Adeniyi, A.A. (2015) Ethical Issues in Newer Assisted Reproductive Technologies: A View from Nigeria. Nigerian Journal of Clinical Practice, 18, 57-61. https://doi.org/10.4103/1119-3077.170823 